\title{
Analysis of typhoon disaster chain and risk management in northward typhoon effecting Hebei
}

Jing Hua ${ }^{1}$, Hu Huifang ${ }^{1 *}$, Chen Xiaolei ${ }^{1}$, Hou Qiqi ${ }^{2}$

1.Hebei Province Meteorological Disaster Prevention Center, Shijiazhuang, Hebei, 050021, China; 2.Langfang Meteorological Bureau, Langfang, Hebei, 065000 996189732@qq.com

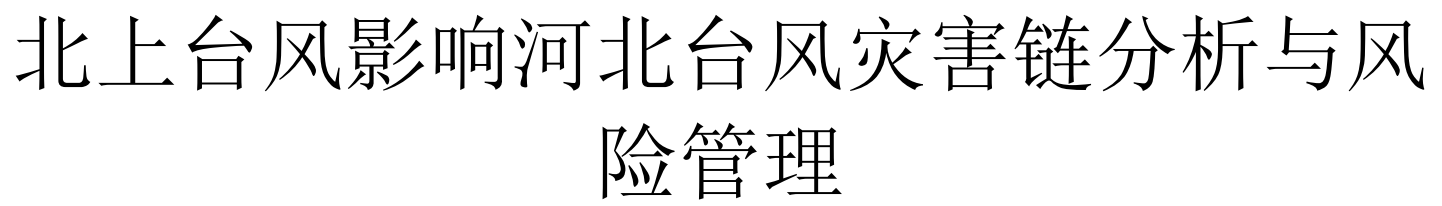

景华 ${ }^{1}$, 胡会芳 ${ }^{1}$, 陈小雷 ${ }^{1}$, 侯奇奇 ${ }^{2}$

1. 河北省气象灾害防御中心，河北省石家庄，050021；2. 廊坊市气象局，河北廊坊，065000 996189732@qq.com

资助项目：环渤海区域科技协同创新基金项目 “北上台风影响河北的灾害链成灾机制以及风险评估模型研 究”(QYXM201803)

\begin{abstract}
Based on northward typhoon effecting Hebei data during1949-2018,key areas were Defining. The climatic features and impacts of typhoons entering the key areas were discussed. The results show that most of northward typhoon effecting Hebei occurred from late July to early August.The northward typhoon entering III district affected Hebei with the highest frequency, and rainstorm, gale and storm surge were easy to happen, Second -ly, it was II, which was to cause coastal and sea winds, When entering I, the TaihangMountains in the south had severe flood disasters. Starting from the disaster system theory, combined with the disaster data, the disaster-preventing environment and the disaster-bearing body information, the typhoon-storm, typhoon- gale, typhoon-storm surge three disaster chains were Built. And accord -ing to different disaster chains, corresponding disaster reduction measures were proposed, provided technical and decision support for the effective management of typhoon disaster risks.
\end{abstract}

Keywords - northward typhoon, affecting key areas, disaster chain, disaster prevention

摘要一利用 1949-2018 年影响河北的北上台风 资料, 划定影响河北的台风关键区, 对进入关键区 的北上台风的气候特征以及影响进行分析发现, 影 响河北的北上台风大多发生 7 月下旬-8 月上旬; 北 上台风进入而区影响河北的频率最高, 暴雨、大风、 风暴潮均易发生; 其次为 II 区, 易引发沿海及海上 大风; 进入 I 区时, 西部太行山暴雨山洪灾害严重。 从灾害系统论出发, 结合灾情资料、孕灾环境和承 灾体构建北上台风影响河北的台风一暴雨, 台风一
大风、台风一风暴潮三种灾害链, 并且针对灾害链 的不同, 提出对应的断链减灾对策, 为有效进行台 风灾害风险管理，提供技术支持和决策支撑。

关键词一北上台风, 台风关键区, 灾害链, 减灾对 策

\section{I. 引言}

台风是一种发生在热带或副热带海洋上的 气旋性浴旋, 是一种破坏性很强的天气系统。 台风灾害是全球发生频率最高影响最严重的 一种自然灾害。中国则是全世界遭受台风灾害 最严重的国家之一。随着经济总量的增加, 台 风灾害的经济损失也呈逐年增加趋势 ${ }^{[2]}$ 。与华 南和华东沿海地区相比, 我国北方地区虽然受 台风影响频率较低, 但一旦有台风北上, 通常 引发重大灾害, 如“75.8”河南大洪水、“85.8” 辽宁洪水、“96.8” 河北暴雨等均源于北上台 风。

北上台风通常是指进入我国华北、东北地 区或在北方近海北上的热带气旋, 是造成我国 北方和黄渤海洪涝、强风、风暴潮灾害的主要 天气系统 ${ }^{[3]}$ 。高松影等 ${ }^{[4]}$ 对 1949-2015 年北上 热带气旋特征进行了研究, 发现中纬转向、高 纬转向和直接北上路径是造成北方强烈降水 和大风的主要路径。研究表明, 台风灾害主要 由台风所带来的狂风、暴雨和风暴潮及其引发 的灾害链所造成的 ${ }^{[5]}$, 史培军等 ${ }^{[6]}$ 指出灾害链 
是指因一种灾害发生而引起的一系列灾害发 生的现象, 并根据灾害系统论, 从宏观上构建 了台风灾害链模式, 潘安定等 ${ }^{[7]}$ 探讨了广东沿 海地区台风灾害链的主要成因和一般规律, 对 台风灾害链的主要环节和类型进行了初步划 分, 陈香 ${ }^{[8,9]}$ 建立了福建省台风灾害链模式并 分析了 “龙王” 和 “桑美” 台风灾害链的成灾 模式, 帅嘉冰等 ${ }^{[10]}$ 分析了长三角地区不同孕 灾环境下的台风灾害链类型及特征, 叶金玉 ${ }^{[11]}$ 分析了福建省台风灾害链的空间分布特征。台 风灾害链分布具有明显的地域差异性, 目前有 关台风灾害链研究主要集中在我国的东南沿 海地区, 而台风北上对北方地区影响致灾的灾 害链分析较少。

本文主要对 1949 年以来影响河北的北上 台风的路径、强度、风雨分布特点以及历史灾 情资料进行分析, 构建北上台风影响河北的灾 害链, 并根据不同地区灾害链发生的可能, 提 出断链减灾对策, 有效进行台风灾害风险管理 提供科学依据。

\section{II. 资料来源及关键区定义}

\section{1 资料来源}

台风资料由中国台风网 “CMSTI 热带气旋 最佳路径数据集” 获取 ${ }^{[12]}$; 受影响区域气象资 料采用国家气象站日数据资料和常规地面观 测资料, 并参考《台风年鉴》和《热带气旋年 鉴》相关资料; 灾害资料来自《中国气象灾害 大典 (河北卷) 》和河北应急管理厅减灾中心 提供。

\section{2 关键区定义}

目前北上台风大多以进入以北纬 $30^{\circ}$ 为 南界、以 $\left(30^{\circ} \mathrm{N}, 125^{\circ} \mathrm{E}\right)$ 和 $\left(35^{\circ} \mathrm{N}, 130^{\circ}\right.$ E) 连点连线为东南边界、以东经 $130^{\circ}$ 为东界 (图 1 中虚线) 所围区域的热带气旋定义为北上 台风 ${ }^{[13]}$ 。根据 1949 年以来影响河北的北上台 风(包括热带气旋以及减弱低压, 以下同) 所 经的区域, 将北上台风区域中以 $32^{\circ} \mathrm{N}$ 为南界、 $120^{\circ} \mathrm{E}$ 为东界的区域作为研究影响河北的北 上台风的关键区。并根据对河北的影响, 将关 键区分为 I 、 II 、III三个区域。其中 I 区主要 是相对河北省以南的区域, II 区是河北省以东
的区域, 而III区为河北省内陆和渤海湾区域 (图 1)。

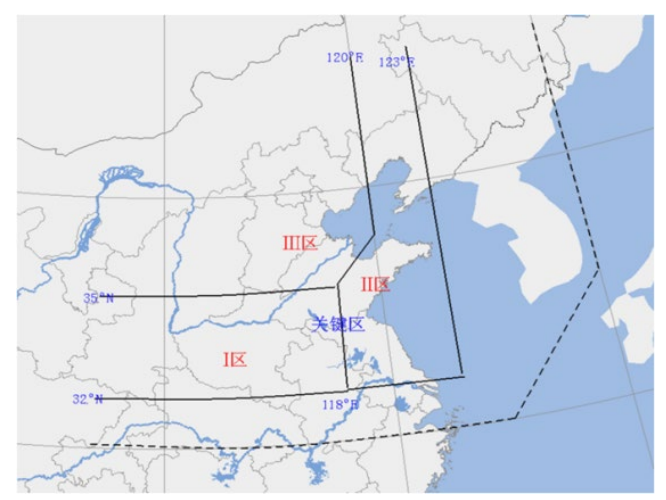

图 1 北上台风影响河北关键区示意图

III. 影响河北的北上台风气候特征及影响

3.1 时间变化特征

1949 年以来, 进入关键区的北上台风共 35 个, 平均约 2 年一次, 但具体个数分布不均, 1994 年最多, 有 4 个北上台风进入关键区, 其次是 2018 年有 3 个进入, 其余年份有一个 或无北上台风影响河北关键区。从年代际分析 20 世纪 50 到 90 年代分别为 3 次、 6 次、6 次、 4 次和 7 次, 2000 年到 2010 年有 5 次为平均 次数, 2011 到 2018 年目前有 4 次, 较平均略 少。

\section{2 影响时间特征}

35 个进入关键区的北上台风 7 月有 14 次、 8 月 19 次、 9 月 2 次，分别占比为 $40 \% 、 55 \%$ 和 $5 \%$, 其中发生在七下八上（7 月 21 日 8 月 10 日）的有 21 次，约占 $60 \%$ 。可见北上台 风关键区的时间主要在 $7 \sim 8$ 月, 特别是 7 月 下旬到 8 月上旬是重点时间段。

\section{3 登陆地点特征}

在我国大陆登陆进入关键区的北上台风, 在福建和浙江登陆的均有 11 次, 其次是山东 7 次。 35 个进入关键区的北上台风其中有 18 次经过关键区 I 区, 其中有 9 次在福建登陆北 上, 有 8 次在浙江登陆北上; 而 17 次经过关 键区 II 区的北上台风中有 8 次在山东登陆。

\section{4 台风强度特征}

影响河北的北上台风首次在我国大陆登陆 且强度达台风级别以上的有 15 次, 强热带风 暴有 12 次分别占比 $43 \%$ 和 $34 \%$ 。而进入关键区 的最高强度达台风级别的仅有 2 次, 占比约 
$6 \%$ 。达强热带风暴和热带风暴的分别有 9 次和 5 次, 而强度为热带低压和减弱热带低压的分 别为 9 次和 10 次, 占比分别为 $26 \%$ 和 $28 \%$ 。可 见北上台风进入关键区后强度明显减弱。

\section{5 进入关键区以及影响特征}

进入关键区的 35 次北上台风中有 9 例仅 经过偏南的关键区 I 区, 占比 $26 \%$; 有 12 例 仅经过偏东的关键区 II 区, 占比 $34 \%$; 进入 主体是河北省的关键区 III 区的有 14 例, 占 比 40\%, 其中有 6 例 (43\%) 由 I 区北上进入 III 区, 而由偏东的 II 区西北上进入 III 区 的有 8 例 $(57 \%)$ 。总体上北上台风以东路径影 响河北偏多。

分析北上台风影响河北的 35 次过程, 发 现进入不同关键区, 北上台风造成的主要影响 （暴雨、大风、风暴潮）和灾害也有所不同。 通过对影响过程的平均降水量、最大降水量、 2 分钟平均风速、最大风速等气象要素和有关 风暴潮及灾情数据分析表明, 北上台风在 I 区 时, 太行山和燕山山前区域平均降水量较大, 极值区位于太行山前。北上台风在关键区 I 区 时虽位置偏南, 但台风外围气流与西风带系统 相互作用, 会造成河北省大范围暴雨成灾, 特 别是太行山南部的暴雨灾害。如 1996 年受 8 号台风（图 2a）外围云团影响，8 月 4、5 日 两天, 邯郸、邢台、石家庄、保定等市连降大 暴雨和特大暴雨, 在 30 个小时的时间内, 雨 量超过 100 毫米的有 51 个县市, 其中超过 200 毫米的有 20 个县市, 超过 400 毫米的有 4 个 县, 处于暴雨中心位置的邢台野门沟水库降雨 616 毫米, 井陉县微水站降雨 670 毫米 (图 2b)。 暴雨造成多地山洪暴发, 河水猛涨, 太行山区 11 座大型水库有 10 座溢洪, 24 座中型水库有 21 座溢洪, 全省有 $2 / 3$ 的县受灾, 特别是西部 太行山区和山前 4 个蓄滞洪区灾情严重, 677 人死亡, 231 人失踪, 130 多万名群众被洪水 围困, 直接经济损失 456.3 亿元。
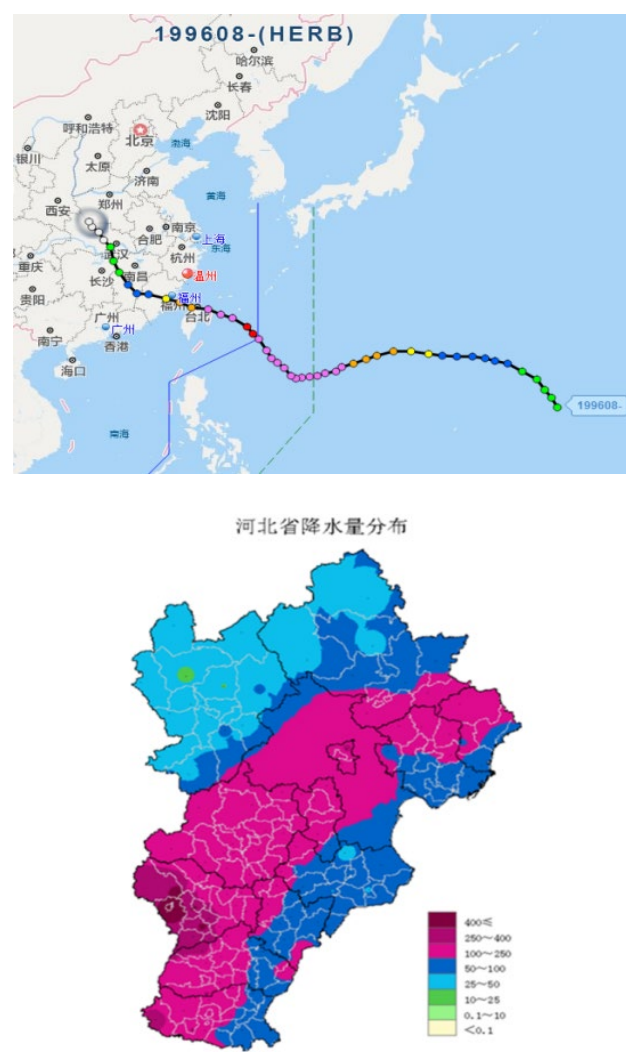

图 29608 号台风路径（a）及河北省受 其影响过程降水量 (b)

北上台风在 II 区时, 易引发沿海以及海上 大风，甚至引发风暴潮，35 次北上台风过程 中, 渤海塘沽港有 11 次出现风暴潮, 其中 9 次是发生在北上台风过关键区 II 区。此外若北 上台风位置靠近III区, 易造成燕山地区暴雨洪 涝灾害。如 8509 台风、0509 麦莎台风等。

当北上台风进入关键区III区时, 河北境内 暴雨、大风、风暴潮均可发生, 带来较为严重 的灾害。如 7203 热带气旋和燕山南麓迎风坡 抬升作用的共同影响, 河北中北部地区燕山南 麓及北京地区出现大暴雨过程, 最强暴雨中心 位于燕山的束树林, $24 \mathrm{~h}$ 降水量 $479.2 \mathrm{~mm}$, 过 程降水量达 $518.3 \mathrm{~mm}$ 。燕山出现泥石流, 渤 海出现 9-12 级的大风和强烈风暴潮, 其中秦 皇岛出现 $2.48 \mathrm{~m}$ 的历史最高潮位。1994 年 7 月 11 日至 13 日, 受 6 号台风影响, 河北省东 部和北部地区降特大暴雨, 廊坊三河市中兆甫 乡降雨 520 毫米, 大厂县夏垫镇日降雨 413 毫 米, 承德兴隆县石洞等乡日降雨 450 毫米引起 山洪暴发, 河水猛涨, 㴒河、武烈河、鲍邱河、 青龙河等出现了几十年未遇的大洪峰。承德、 唐山、秦皇岛、廊坊多县市受灾, 公路、铁路、 
供电、通讯等基础设施遭到严重破坏。

\section{IV. 灾害链分析}

利用案例透析法对北上台风造成的影响 进行系统分析, 从灾害系统论出发, 结合河北 省特殊的孕灾环境和承载体, 构建北上台风影 响河北灾害链,包括台风一暴雨、台风一大风、 台风一风暴潮 3 种类型, 不同灾害链重点关注 的致灾方式不同。
台风一暴雨灾害链中（图 3), 要关注暴 雨山洪灾害, 特别是河北省西部的太行山东麓 和北部燕山南麓地区, 一旦暴雨引发山洪, 常 引发山区和下游平原地区的洪涝灾害, 特别是 对农、林业以及水利、电力、通讯、交通、能 源等设施和产业损害严重, 给群众人身安全和 社会财产造成严重危害。

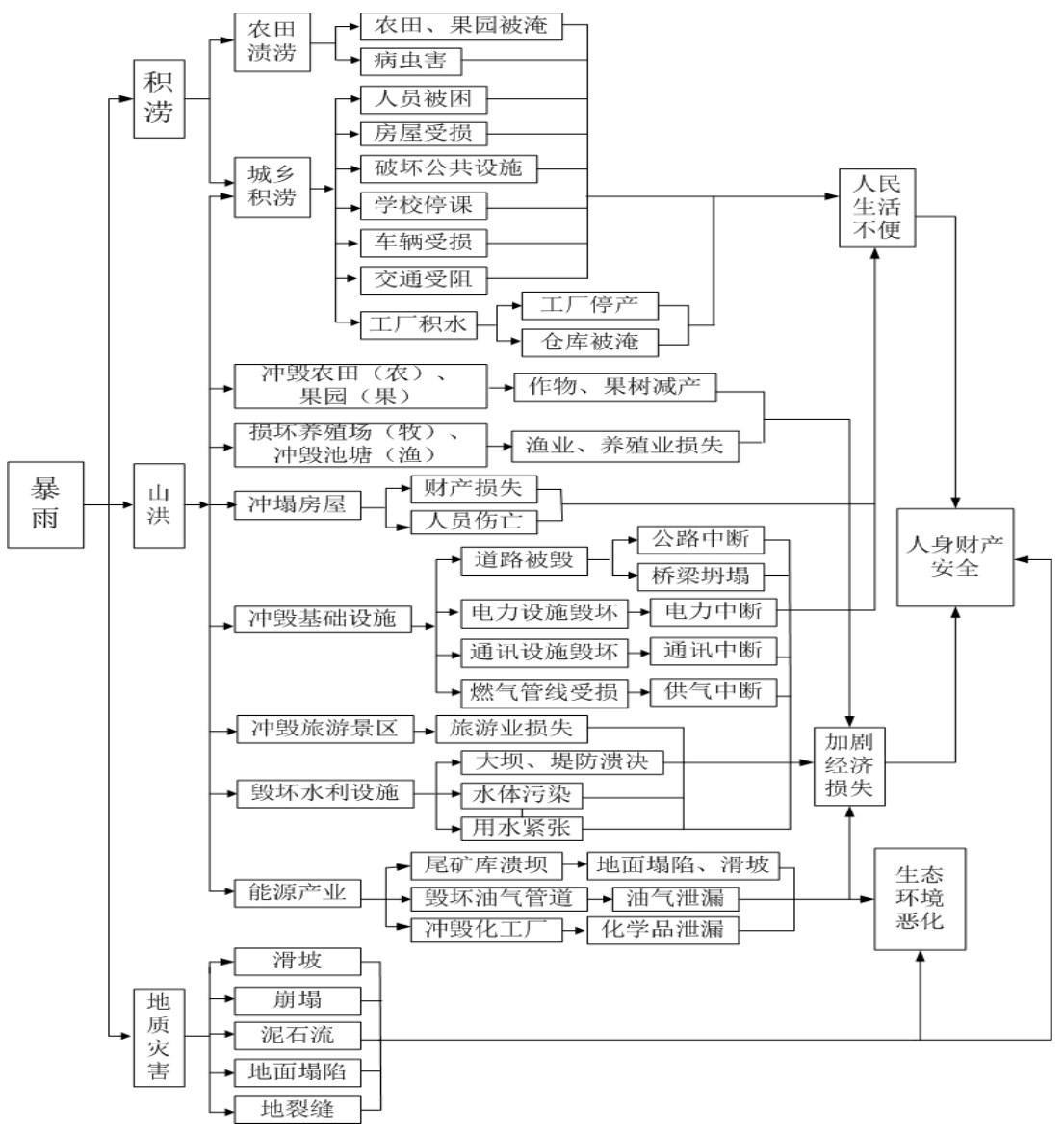

图 3 台风-暴雨灾害链

台风一大风灾害链中（图 4), 要关注海 上大风浪及涌浪的影响, 沿海地区人口以及设 施较密集, 大风造成的损失也较严重, 特别是
对渔业、交通、旅游以及沿岸基础设施等影响 严重; 在内陆地区大风的强度较沿海和海上要 弱, 大风破坏能力相对沿海和海上要小。 


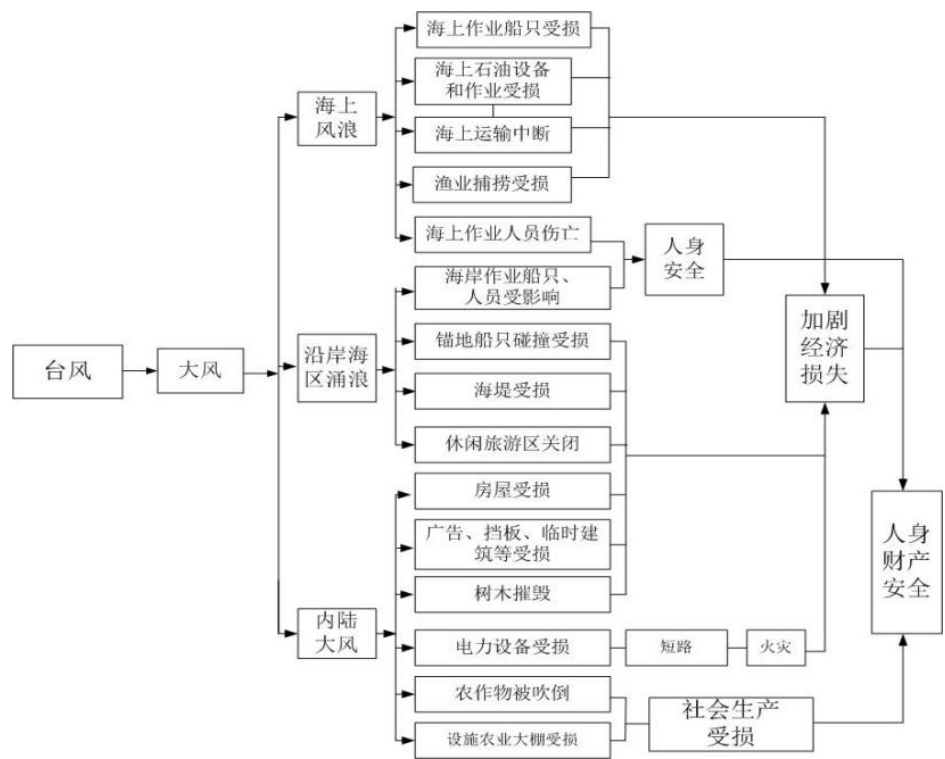

图 4 台风一大风灾害链

台风一风暴潮灾害链中（图 5), 要关注态环境、公共基础设施等造成严重影响, 给群 海水倒灌的情况, 一旦发生会给沿海地区的生众生活和社会生产造成严重损失。

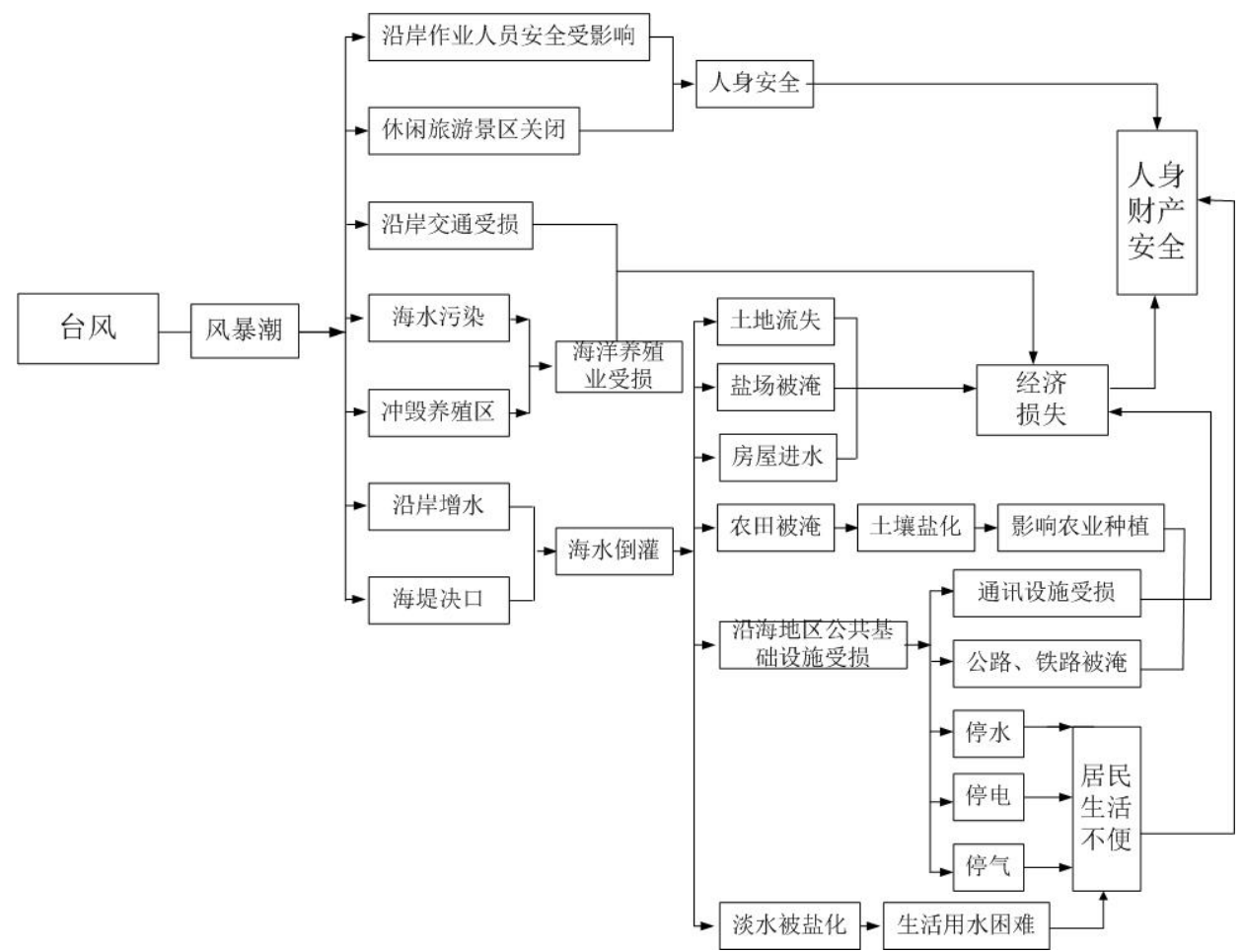

图 5 台风一风暴潮灾害链

V. 有针对性的灾害风险管理

灾害风险管理是从根源上对灾害风险加 以控制, 通过减少灾害事件的发生或通过预防 性的措施减少灾害造成的损失。北上台风灾害 风险管理应在积极监测、及时预警灾害发生可 能性的同时，构建包括致灾因子、孕灾环境、 承灾体脆弱性以及防灾减灾能力等信息的大 数据平台, 建立信息跨部门共享机制, 加强部
门合作，提升应急处置能力。在灾害风险判断 和灾害防御准备时要有针对性加强防御重点。 北上台风进入不同的影响关键区, 其关注的重 点灾害以及灾害链孕源断链防御对策也不同。

北上台风进入 I 区时, 台风一暴雨灾害链 是关注重点, 特别是在太行山区和南部平原, 应研发和使用高精度、全天候、自动化、远程 实时监测预警的专业系统 ${ }^{[14]}$ 。加强对山洪、地 
质灾害、洪涝以及城市内涝等灾害的监测、预 警和防御, 并关注台风路径的变化, 尤其特别 关注是否有西风带系统与减弱的台风低压结 合影响其他地区。加强灾害发生时的紧急避难 工作准备, 暴雨到来时迅速制订科学的救灾治 灾案, 尽快恢复生产及灾后重建工作等, 而更 重要的是要在灾害来临之前, 力求及早切断灾 害链的主要环节, 减少连续性灾害的损失 ${ }^{[7]}$ 。 台风季之前组织暴雨应急演练, 加强水库、河 流巡查工作，对易发生崩塌、滑坡、泥石流等 灾害的隐患点进行提前治理、定期监测, 同时 采用一定的工程措施进行预防, 加强通讯设施 的维护和应急设备的准备, 暴雨发生前和发生 时能及时将预报预警传递给公众, 树立警告牌 等, 并及时将上游地区以及本区域的雨情、水 情、灾情等信息传递给政府决策部门, 各个部 门高效联动共同防御灾害。

进入 II 区的北上台风，要关注台风一大风、 台风一风暴潮灾害链以及燕山地区的台风一 暴雨灾害, 应加强对台风路径的预报预警、加 强沿海、海上地区以及燕山山区的灾害防御。 建立和完善相应的综合减灾管理体系, 由于 II 区台风对沿海和海上地区影响较大, 气象、 海洋、水利等部门应建立相应的综合减灾管理 体系, 完善综合自然灾害监测网络, 建立统一 的信息共享机制和技术规范, 加强对灾害链的 综合防御能力。对于沿海大风和风暴潮灾害, 加强海堤工程与防护林的建设和维护, 可以有 效削弱到达陆地的风暴潮能量, 实现断链防御 [15]。

进入III区的北上台风会直接影响河北, 常 造成较为严重的影响, 台风一暴雨、台风一大 风、台风一风暴潮 3 种灾害链均需重点关注, 山区、沿海以及城市均需加强有针对性的防御。 进入关键区III区的北上台风对河北影响大, 但 只要防御及时、措施得当, 灾害损失会减轻, 灾害影响会减小。如 2018 年先后有三个台风 北上影响河北省, 其中第 10 号台风 “安比” 是 1949 年以来首个以热带风暴级别进入河北 省陆地的台风, 由于及时发布了台风、暴雨等 预警信号和山洪、地质灾害、渍涝等风险预警, 相关部门积极应对, 虽然使河北承德、秦皇岛 等地多处河道涨水明显, 部分河道出现洪水, 多地出现严重的城市内涝, 农作物遭受不同程
度的渍涝灾害, 但 “安比” 并未造成河北人员 伤亡, 直接经济损失 3.3 亿元, 比仅进入关键 区 I 的台风 “摩羯” 的直接经济损失还小。

VI. 总结和讨论

1. 北上台风多在 7 月下旬 -8 月上旬影响 河北, 北上台风进入关键区 III 区影响河北的 频率最高, 暴雨、大风、风暴潮灾害均易发生; 其次为 II 区, 易引发沿海及海上大风; 进入 I 区时, 易发生暴雨灾害, 特别是西部太行山暴 雨山洪灾害严重。认识和理解影响河北的北上 台风特点以及影响特征, 有利于进行有针对性 的台风灾害风险管理, 减小台风灾害损失。

2. 河北省东频渤海, 西倚太行山, 南接黄 淮平原, 北连蒙古高原, 不同区域, 北上台风 致灾链条不同。台风-暴雨、台风一大风、台风 一风暴潮三种灾害链, 不同灾害链重点关注的 致灾方式不同。台风一暴雨灾害链中重点关注 暴雨山洪灾害, 台风一大风灾害链中重点关注 海上大风浪及涌浪的影响, 台风一风暴潮灾害 链要关注海水倒灌情况的发生。

3. 北上台风进入不同的影响关键区, 其关 注的重点灾害以及灾害链孕源断链防御对策 也不同。有针对性进行灾害风险管理能更高效、 科学的预防、应对台风对河北的影响。北上台 风进入关键区 I 区时, 台风一暴雨灾害链是关 注重点, 尤其要做好山区山洪和平原洪涝灾害 防御工作, 特别是太行山区和南部平原是防御 的重中之重; 进入 II 区的北上台风, 要关注台 风一大风、台风一风暴潮灾害链以及燕山地区 的台风一暴雨灾害的防御和应对; 进入III区的 北上台风会直接影响河北, 常造成较为严重的 影响, 台风一暴雨、台风一大风、台风一风暴 潮 3 种灾害链均需重点关注。山区、平原、沿 海均需加强有针对性的防御和应对。

\section{参考文献}

[1] Schmidt S,Kemfert C,Hppe P . The impact of socio-economics and climate change on tropical cyclone losses in the USA[J].Regional Environmental Change, 2010, 10( 1$): 13-23$.

[2] Zhang Q,Wu L,Liu Q. Tropical Cyclone Damages in China 1983-2006[J].Bulletin of the American Meteorological Society,2009,90( 4) : 489-495.

[3]王秀萍,梁军. 近 52 年北上热带气旋的若干气候特征 [J]. 气象, 2006,32(10):76-80. 
[4]高松影, 赵婷婷, 宋丽丽, 等. 1949-2015 年北上热带气旋 特征.[J].气象科技,2017,45(2):313-323.

[5]梁必骐, 梁经萍, 温之平. 中国台风灾害及其影响的研究

[ J].自然灾害学报, 1995, 1(4):84

[6]史培军.三论灾害研究的理论与实践 [J]. 自然灾害学 报,2002,11(3)1-9.

[7]潘安定,唐晓春, 刘会平.广东沿海台风灾害链现象与防 治途径的设想 $[\mathrm{J}]$. 广州大学学报: 自然科学版,2002,1 (3) : 55-61.

[8]陈香,陈静,王静爱. 福建台风灾害链分析一以 2005 年 “龙王”台风为例 $[\mathrm{J}]$. 北京师范大学学报: 自然科学版, 2007,43 (2) : 203-208.

[9]陈香.福建 0608 号超强台风“桑美”灾害分析 [J] . 亚热 带资源与环境学报,2007,2 (3) : 35-41.

[10]帅嘉冰,徐伟,史培军. 长三角地区台风灾害链特征分析 [j].自然灾害学报,2012,21 (3):36-42.

[11] 叶金玉,林广发,张明锋. 福建省台风灾害链空间特征 分析饥 [J]. 福建师范大学学报(自然科学版),2014,30(2):

99-106

[12]Ying, M., W. Zhang, H. Yu, X, etal. An overview of the China Meteorological Administration tropical cyclone database [J]. Atmos. Oceanic Technol,2014: 31, 287-301.

[13]王达文. 北上热带气旋分析与预报 [M]. 北京: 气象 出版社,2001:17-18.

[14]王萌,田伟平, 崔英强. 陕西省暴雨灾害链实例分析及 综合减灾对策[J].风险管理，2011,7（29）:69-71.

[15]王可,钟少波,杨永胜,等.海洋灾害链及应用[J].灾害学, 2018,33(4):229-234. 